Rev. Elet. em Gestão, Educação e Tecnologia Ambiental (e-ISSN: 2236-1170)

\title{
A HERMENÊUTICA DA EDUCAÇÃO AMBIENTAL E O PARADOXO DA SUSTENTABILIDADE
}

\author{
Eduardo Beltrão de Lucena Córdula', Glória Cristina Cornélio do Nascimento² \\ ${ }^{1}$ Licenciado em Biologia (UFPB); Especialista em Educação (IESP); Pesquisador do GEPEA (UFPB/CE); Professor da \\ Prefeitura de Cabedelo-PB; e-mail: ecordula@hotmail.com \\ ${ }^{2}$ Licenciada em Biologia (UNAVIDA); Mestranda do PRODEMA (UFPB); e-mail: gccornelio@hotmail.com
}

http://dx.doi.org/10.5902/223611706670

\section{RESUMO}

A sociedade contemporânea busca atualmente reverter os graves danos causados ao planeta e que afetam diretamente nosso modo de vida, pelos transtornos ambientais globais e que trazem como consequência, danos às formas de vida existentes. Este paradigma se deve a uma percepção social e ambiental dicotomizada, que mesmo com o surgimento da Educação Ambiental na década de 60 , em seus 50 anos de atuação, pouco conseguiu mudar na visão do ser humano sobre si mesmo e sobre este planeta, gerando uma corrida "verde" de desenvolvimento longe ainda do ideal, o que fez surgir uma pseudosustentabilidade, com vistas apenas a preservação e conservação dos recursos naturais. Porém, com a Hermenêutica aliada as questões ambientais, lançou um novo olhar de interpretação sobre os fenômenos neste planeta, trazendo a sensibilização para gênese da tomada de consciência necessária as verdadeiras mudanças ao ser humano e seu agir sobre o planeta, unindo sociedade e meio ambiente, através da Educação Socioambiental para tomada de um desenvolvimento agora sustentável, buscando assim, qualidade de vida socioambiental para estas e as futuras gerações.

Palavras-Chave: Educação Ambiental; Educação Socioambiental; Sustentabilidade.

\section{ABSTRACT}

Contemporary society is currently seeking to reverse the severe damage to the planet, and that directly affect our way of life, the global environmental and disorders that bring as a consequence, damage to life forms. This paradigm is due to a perceived social and environmental dichotomized, that even with the emergence of Environmental Education in the 60's, in its 50 years of operation, some managed to change the vision of man about himself and about this planet, generating a race "green" development still far from ideal, which brought about a false-sustainability, aiming only the preservation and conservation of natural resources. However, with the Hermeneutics allied environmental issues, has launched a new look for the interpretation of the phenomena on this planet, bringing awareness to the genesis of awareness of the real changes necessary to humans and their actions cork planet, uniting society and environment through the environmental Education for taking a sustainable development now, aiming thus environmental quality of life for these and future generations

Keywords: Environmental Education, Socioenvironmental Education, Sustainability. 
Rev. Elet. em Gestão, Educação e Tecnologia Ambiental (e-ISSN: 2236-1170)

\section{Introdução}

Enquanto o mundo avança na era da globalização e das novas tecnologias, que buscam dinamizar nosso modo de vida e, como consequência nos distanciou cada vez mais da nossa condição humana neste planeta, que seria uma condição de socialização e o interligação com o ambiente natural (CÓRDULA, 2010a). A sociedade continua a se desenvolver, criando um paradigma que entra em choque com problemas seculares da humanidade: fome, miséria e desigualdades sociais, convertendo-se numa paradoxo que se soma a uma crise ambiental que determinará o nosso futuro (CAPRA, 2006). Este modelo de desenvolvimento se deve a um modelo cartesiano e mecanicista que foi implantado na sociedade, em que analise toda a ciência e a condição humana em partes e despreza o todo, por uma analogia, podemos comparando vida a uma máquina em que estudamos a suas "peças" (partes) para então, compreender seu funcionamento (CÓRDULA; NASCIMENTO, 2012a). Porém, esta visão dualista - cartesiana e mecanicista - deixa de compreender e analisar toda a complexidade que compõe as interligações planetárias que dão suporte a vida neste planeta, e, como consequência, possibilitam o desenvolvimento da humanidade através do consumo dos recursos naturais existentes (LOVELOCK, 2006). Há, portanto, uma necessidade eminente de mudança desta concepção e percepção dualista, que acaba dicotomizando as ciências da natureza das ciências humanas, e é através dos estudos em ecologia, dos movimentos ecoambientais e, sobretudo da Educação Ambiental e Socioambiental que estas mudanças ocorreram na sociedade, traçando um novo paradigma sustentável (NASCIMENTO; CÓRDULA, 2012; MADONESE, 2012).

\section{Educação (Sócio)Ambiental e Hermenêutica}

A Educação Ambiental $(E A)^{1}$, cuja expressão é de origem inglesa (Environmental Education), elaborada durante a Conferência de Educação da Universidade de Keele, na Inglaterra, em 1965 (BRASIL, 1998), para tratar de sensibilizar o ser humano sobre seu papel na conservação e preservação dos recursos naturais do planeta. A EA está a 50 anos atuando como uma concepção pedagógica alternativa para gênese de práticas ambientais pelos cidadãos da sociedade contemporânea, com visas à qualidade de vida ambiental (DIAS, 1998). A EA tem em sua conotação mais simples: educar para um ambiente saudável e a pesar de existir várias definições, sua concepção é mais abrangente do que se imagina, pois trabalha com o consciente e o inconsciente humano, visando despertá-lo para a proteção do meio ambiente (CÓRDULA, 2010a).

A EA é o encontro real da fusão entre a razão e a emoção, não distante da educação formal, ensinado a criança a usar sua criatividade e a pensar no amanhã, de forma crítica para que se tornem cidadãos conscientes, defensores de seus direitos e cumpridores dos seus deveres para com a vida, a sociedade e a família (CÓRDULA, 2010b, p. 11).

Porém, atualmente, o que é perceptível é que a EA por si própria não conseguiu ainda que o ser humano passe a ter conhecimentos necessários ao desenvolvimento das práticas

$1 \quad$ EA - Educação Ambiental 
Rev. Elet. em Gestão, Educação e Tecnologia Ambiental (e-ISSN: 2236-1170)

sustentáveis que levam a mudanças de comportamento, já que os problemas ambientais continuam a reincidir sobre as comunidades e a sociedade (CÓRDULA, NASCIMENTO, 2012b). As mudanças necessárias na população devem surgir de uma mudança de valores e de percepção de si mesmo sobre o planeta e a vida, para que o ser humano passe a desenvolver um Comportamento Ambientalmente Responsável (CAR), que só é possível através da hermenêutica ambiental (NASCIMENTO; CÓRDULA, 2012).

A hermenêutica é um termo de origem etimológica grega (hermeneuein), cuja epistemologia moderna lhe designa como a teoria ou a filosofia da interpretação, que viabiliza a percepção dos fenômenos, indo além de sua simples aparência (MELLO, 2010). Para Heidegerr (1997), sua significância está na compreensão do mundo a nossa volta.

A união da hermenêutica (...) leva o intérprete a entender o texto, a fala, o depoimento, corno resultado de um processo social (trabalho e dominação) e processo de conhecimento (expresso em linguagem), ambos fruto de múltiplas determinações, mas com significado específico (MINAYO, 1996, p. 227).

Esta abordagem qualitativa traz a luz da interpretação por uma nova ótica, onde a complexidade sistêmica dos fatos e fenômenos predomina, dando um panorama amplo de percepção ao pesquisador, indo além do exposto e buscando as conexões intrínsecas envolvidas no equilíbrio do planeta (WELLER, 2010). Na Educação Ambiental, a hermenêutica une saberes, filosofias e concepções do ser humano sobre si mesmo e sobre seu papel neste planeta (NASCIMENTO; CÓRDULA, 2012).

Ao se trabalhar com educação, meio ambiente e sociedade, visando mudanças de atitudes e valores no ser humano, entram a pedagogia que trouxe à luz das experiências e trabalhos desenvolvidos na área comportamental e ambiental, juntamente com a hermenêutica, propiciando a transmutação da EA para o surgimento da Educação Socioambiental (ESA) ${ }^{2}$, uma abordagem mais centrada na entidade humana, nas suas experiências e vivências, deixando de lado o tecnicismo e a tentativa de simplesmente "conscientizar", para sensibilizar o ser humano, através de seus problemas sociais e ambientais, mostrando a relações sistêmicas envolvidas, onde um afeta diretamente o outro, numa retroalimentação negativa sem precedentes (CÓRDULA, 2009; 2010a; 2012a).

Quando se lança mão não só de uma pedagogia, mas de uma ecopedagogia aliada a uma psicologia ambiental é possível concretizar ações verdadeiramente capazes de estimular o ser humano, resgatando sua humanidade tão distorcida como nos dias atuais (GADOTTI, 2000). Sendo sensibilizado, passa a se reconhecer como agente ativo de mudanças e passa também, a conhecer o ambiente ao seu redor e atua de forma a preservá-lo (DIAS, 1998). Abandonando a visão egocêntrica e antropocêntrica que fragmenta os componentes de nosso planeta, e adquirindo uma visão holística e das interdependências, passa-se a considerar a Terra como um ente "vivo", em virtude de toda a sua dinâmica, e desta forma, consegue-se preservá-la (CAPRA, 2006).

Um dos parâmetros para atuar diretamente com a ESA no ensino formal, é a teoria de Gaia, do pesquisador James Lovelock (2006), que considera o planeta como um organismo, para que o público infanto-juvenil, em formação não só cognitiva, mas também da sua percepção e concepções de mundo, compreendam a Terra como parte integrante de duas vidas, onde todas as partes vivas e não-vivas estão interligadas, num processo rítmico de fluxo constante de energias

2 ESA - Educação Socioambiental 
Rev. Elet. em Gestão, Educação e Tecnologia Ambiental (e-ISSN: 2236-1170)

vitais ao equilíbrio planetário, e que, nossas ações consumistas sem consciência, trazem danos irreversíveis que se repercutem a nível global, ao delicada manutenção da vida. Sensibilizados, com uma nova gênese de consciência e percepção, teremos ecocidadãos que poderão não mais ficar apáticos frente aos graves problemas ambientais que estão sendo enfrentados e que estão culminando para uma grave crise ambiental sem precedentes e talvez, se não mudarmos hoje e já, irreversível (CÓRDULA, 2009).

Quando lançamos mão não só de uma pedagogia, mas uma ecopedagogia aliada a uma psicologia ambiental foi possível concretizar ações verdadeiramente capazes de estimular o ser humano, resgatando sua humanidade tão distorcida como nos dias atuais. Se reconhecendo e conhecendo o ambiente ao seu redor, o ser humano passa a atuar de forma a preservá-lo (CÓRDULA, 2009, p.02).

Por esta razão, não se pode fazer ESA apenas por modismos, como ocorrem principalmente nas esferas educacionais ou simplesmente para fins pessoais, mas sim, por filosofia de vida e por acreditar que algo pode ser feito para trazer qualidade de vida socioambiental para estas e as futuras gerações, trazendo uma verdadeira sustentabilidade para as sociedades, caso contrário continuaremos em uma pseudosustentabilidade (CÓRDULA, NASCIMENTO, 2012b,c).

\section{O Paradoxo da Sustentabilidade}

Segundo BOFF (2012), sustentabilidade são todos os processos envolvidos na manutenção da vitalidade do planeta, com a preservação e conservação dos recursos naturais, propiciando a continuidade de vida de todas as espécies, concomitantemente, com o desenvolvimento da humanidade, para atender as presentes e as futuras gerações.

Há uma crescente falta de consenso no que diz respeito à palavra sustentável ou desenvolvimento sustentável, que para Abílio e Guerra (2006), e Dias (1998), são recursos bem utilizados hoje para que as futuras gerações se beneficiem. Esta concepção provocou um equívoco na percepção e na responsabilidade ambiental do ser humano, pois gerou uma corrida a chamada "Era Verde", com foco direto para a conservação das áreas naturais, o que acabou deixando ao esquecimento o modo de vida consumista e que leva portanto à geração de resíduos nas sociedades, o que, por um lado, agravou a qualidade de vida do ser humano e por outro, atingiu diretamente o planeta, pela emissão de poluentes (CAPRA, 2006; CÓRDULA, 2010a; DIAS, 2004). Podemos conceber, então, um período de pensamento incompleto da nossa concepção de sustentável a expressão, e que na verde estávamos tratando de uma pseudosustentabildiade ${ }^{3}$, pois não abarcava toda a complexidade planetária da teia que sustenta o frágil equilíbrio da vida, e portanto, da nossa própria espécie em sociedade e no planeta (NASCIMENTO; CÓRDULA, 2012a,c).

Desenvolvimento e crescimento são palavras bastante distintas e não levam soluções ideais para uma melhor utilização de recursos naturais no planeta, pois, segundo Diegues (2001), devem se levar em conta o reconhecimento da existência de uma grande diversidade ecológica, biológica e cultural entre povos que nem a homogeneização sociocultural imposta pelo mercado

\footnotetext{
${ }^{3}$ Pseudosustentabilidade = ou falsa sustentabilidade. Termo empregado para designar quando não se há uma ação, pensamento ou intenção verdadeiramente sustentável (CARDOSO, 2012; PIRES, 2009).
} 
Rev. Elet. em Gestão, Educação e Tecnologia Ambiental (e-ISSN: 2236-1170)

capitalista mundial, nem os processos de implantação do "socialismo real" conseguiram destruir. Para Guimarães (1994 apud AMSTALDEN, 1996), esta diversidade de interesse e opiniões está profundamente ligada às diferenças socioeconômicas, políticas e geopolíticas entre grupos sociais, classes, setores empresariais, países e regiões.

As questões econômicas têm como base a industrialização, que por sua vez não está em harmonia com a natureza, pois visa lucro a custos de extração dos recursos naturais e não deixa que esses sejam externalizados em seu tempo necessário. Então, como se desenvolver a custos tão altos? Como crescer se a equidade mundial está longe de se alcançar? São paradigmas e paradoxos a serem pensados nos modelos econômicos que utilizam atualmente o marketing "verde" para se promoverem, pois, esse termo vem associado ao bem-estar e, que se comprando produtos ecologicamente corretos, estaremos fazendo nossa parte dentro do modelo sustentável planetário (NASCIMENTO; CÓRDULA, 2012).

Segundo Guimarães (1995), existe uma tendência inercial do sistema para resistir às mudanças, promovendo a aceitação do discurso transformador, precisamente para garantir que nada mude. A mudança de visões e interesses econômicos depende de atitudes em longo prazo, o que implica não condizer com o desenvolvimento sustentável, surgindo, portanto, um grande abismo entre os conceitos já que o mercado tem necessidades imediatas (NASCIMENTO; CÓRDULA, 2012). Assim, o desenvolvimento sustentável necessita antes de tudo de um estado articulado e forte o suficiente para promover, incentivar e, quando for o caso, impor diretrizes e normas para atingir essas mudanças (AMSTALDEN, 1996). Não se pode esquecer da cidadania participativa neste contexto tão polêmico, pois é de tamanha e crucial importância a sua inclusão.

Para Vernier (1994), a solução está em seis alavancas de ação: (1) Leis; (2) Estímulos econômicos e fiscais; (3) Cidadãos e associações ativas; (4) Uma educação sobre o meio ambiente e; (5) Uma ação internacional. Para Nascimento e Córdula (2012), deve-se adequar o modo de vida da sociedade contemporânea, a utilização dos recursos naturais e o desenvolvimento de políticas que incentivem o modo de vida sustentável, aliados a projetos e ações em Educação Socioambiental, para estagnação dos problemas ambientais e continuação do desenvolvimento da sociedade e busca do equilíbrio planetário.

Encarar estes problemas como se fossem separados e não relacionados conduz a soluções de curta duração e pouco alcance, que muito frequentemente criam mais problemas ambientais de logo alcance que os que são resolvidos (TANNER, 1978).

\section{Considerações Finais}

O ser humano no seu processo de desenvolvimento da sociedade criou problemas ambientais que atingiram uma ótica planetária, em virtude de um modo de vida socioeconômico, que busca estimular o consumismo alimentado pela exploração dos recursos naturais do planeta. Há décadas estudos e pesquisas tentam direcionar a percepção do ser humano sobre si mesmo e sobre sua responsabilidade planetária, para conduzir a sociedade contemporânea no resgate do equilibro do ser humano com o planeta, através principalmente da Educação Ambiental (EA), que poucos resultados trouxe, frente a amplitude das questões ambientais e que envolvem diretamente a sociedade.

Nesta sensibilização do ser humano, peça-chave do processo de transformação do planeta em busca do equilíbrio sustentável, está à hermenêutica, que traz a luz uma mudança também de 
Rev. Elet. em Gestão, Educação e Tecnologia Ambiental (e-ISSN: 2236-1170)

percepção sobre nós mesmos e com vistas ao entendimento da complexidade sistêmica das relações vitais no planeta. Sendo assim, transmutou a EA para termos a Educação Socioambiental (ESA), que propicia a sensibilização de nossa espécie sobre si mesma, sobre a sociedade contemporânea, nosso modo de vida e nossa relação com este planeta, que até então era de desequilíbrio, para traçar novos rumos, com mudanças necessárias para atingirmos uma consciência para uma nova filosofia de vida, de percepção e de Comportamentos Ambientalmente Responsáveis.

E através de pesquisas, programas, projetos e ações em ESA que entenderemos as relações intrínsecas e sistêmicas necessárias a nossa mudança de percepção perante nosso papel neste planeta, garantindo assim, modos de vida verdadeiramente sustentáveis para estas gerações, e assim, garantir a estagnação dos problemas ambientais e reversão do atual quadro de devastação e consumo dos recursos naturais, gênese de qualidade de vida, preservação/conservação do meio ambiente, ascensão da sociedade contemporânea rumo a homeostase ambiental para, também, as futuras gerações.

\section{REFERÊNCIAS}

ABÍLIO, Francisco Pegado; GUERRA, Rafael Angel Torquemada. Educação Ambiental na Escola Pública. João Pessoa: Fox, 2006. 234p.

AMSTALDEN, Luiz Fernando F. Desenvolvimento Sustentável e Pós Modernidade. In: RODRIGUES, Arlete M. (Org). Desenvolvimento Sustentável: Teorias, Debates, Aplicabilidades. Campinas, SP: IFCH/UNICAMP, Textos Didáticos no 23, Maio 1996. pag. 49-72.

BOFF, Leonardo. Sustentabilidade: o que é e o que não é. Petrópolis, RJ: Vozes, 2012, 189p.

BRASIL. A Implantação da Educação Ambiental no Brasil. Brasília: MEC, 1998.

CAPRA, Fritjof. O Ponto de Mutação. 26ạ reimpressão. Tradução Álvaro Cabral. São Paulo: Cultrix, 2006. 447p.

CARDOSO, André Coimbra Felix. O Programa Estratégico Integrado de Gestão para o Desenvolvimento Sustentável. São Paulo: USP, Tese de Doutorado, 2012, 261p.

CÓRDULA, Eduardo Beltrão de Lucena. Novos Rumos da Educação Sócio-Ambiental. Revista Educação Ambiental em Ação, Novo Hamburgo-RS, Ano VIII, N²9, set.-nov./2009. Disponível em: http://www.revistaea.org/artigo.php?idartigo=732\&class=04. Acesso em: 15 set. 2009.

- Meio Ambiente, Ser Humano e Aquecimento Global. Revista Educação Ambiental em Ação, Novo Hamburgo-RS, Ano IX, No 34, dez.2010/fev.2011. Disponível em: http://www.revistaea.org/artigo.php?idartigo=992\&class=02. Acesso em: 10 dez. 2010a.

. Educação Ambiental na Escola. Cabedelo,PB: EBLC, 2010b, 22p. 
Rev. Elet. em Gestão, Educação e Tecnologia Ambiental (e-ISSN: 2236-1170)

. Educação SocioAmbiental Integradora - ESAI. Cabedelo, PB: EBLC, 2012, 35p.

CÓRDULA, Eduardo Beltrão de Lucena; NASCIMENTO, Glória Cristina Córnélio. A Era do Ser Ambiental. Revista de Educação Pública, Rio de Janeiro-RJ, $n^{\circ} 21$, jun/2012a. Disponível em: http://www.educacaopublica.ri.gov.br/biblioteca/meioambiente/0034.html. Acesso em 06 jun. 2012.

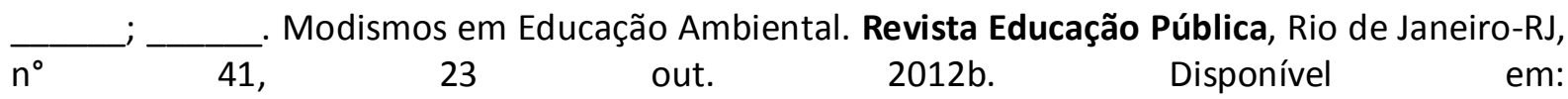
http://www.educacaopublica.rj.gov.br/biblioteca/meioambiente/0035.html. Acesso em: 25 out. 2012.

$\overline{\mathrm{n}^{\circ}} ;-\begin{array}{cccc}\text { 43, } & \text { Pseudosustentabilidade Ambiental. Revista Educação Pública, Rio de Janeiro-RJ, } \\ 06 & \text { nov. } & \text { 2012c. } & \text { Disponível }\end{array}$ http://www.educacaopublica.rj.gov.br/biblioteca/cidadania/0151.html. Acesso em: 08 nov.. 2012.

DIAS, Genebaldo Freire. Educação Ambiental: Princípios e Práticas. 5a ed. São Paulo: Gaia, 1998. . Ecoperceção: um resumo didático dos desafios socioambientais. São Paulo: Gaia, 2004.

DIEGUES, Antônio Carlos S. Ecologia Humana e Planejamento Costeiro. 2o ed. São Paulo: NUPAUB-USP, 2001.

GADOTTI, Moacir. A Ecopedagogia como pedagogia apropriada ao processo da Carta da Terra. Fórum Nacional de Pedagogia - UFMT, 2000. Disponível em: http://www.ufmt.br/revista/arquivo/rev21/moacir gadotti.htm. Acessado em: 21 mar. 2009.

GUIMARÃES, Roberto P. O Desafio Político do Desenvolvimento Sustentável. Revista Lua Nova, no 35, São Paulo, 1995, p. 113-205.

HEIDEGERR, Martin. Ser e Tempo. Rio de Janeiro: Vozes, 1997.

MELLO, Bianca Vieira. Hermenêutica: origem, significado e atuação. Direito Net, 29 abr. 2010. Disponível em: http://www.direitonet.com.br/artigos/exibir/5707/Hermeneutica-origem-significado-e-atuacao. Acesso em: 30 out. 2012.

MINAYO, Maria Cecília de Souza. O Desafio do Conhecimento - Pesquisa qualitativa em saúde. 4a ed. São Paulo: Hucitec-Abrasco, 1996.

LOVELOCK, J. A Vingança de Gaia. São Paulo: Intrínseca. 2006. 160p.

MODANESE, Ione Aparecida Zucchi. Diferentes Concepções de Natureza. Disponível em: http://egal2009.easyplanners.info/area07/7201_ione_ione_Aparecida_Zucchi_Modanese.pdf.

Acesso em 27 out. 2012. 
NASCIMENTO, Glória Cristina Cornélio; CÓRDULA, Eduardo Beltrão de Lucena. Hermenêutica Ambiental e Educação: tecendo saberes e pensamentos. In: CANANÉA, Fernando Abath. Educação Dialoga. João Pessoa: IMPRELL, 2012, p.63-80.

PIRES, Marina Salin. Turismo e Pós-Modernidade: teoria, cultura e sustentabilidade. Brasília, DF: UnB, Dissertação de Mestrado, 2009, 142p.

TANNER, Tommas. R. Educação Ambiental. Tradução George Schesinger. São Paulo: Summus, 1978. 158p.

VERNIER, J. O Meio Ambiente. 2a ed. Tradução de Maria Appenzeller. Campinas, SP: Papirus, 1994.

WELLER, Wivian. Aportes Hermenêuticos no Desenvolvimento de Metodologias Qualitativas. Linhas Críticas, Brasília, DF, v. 16, n. 31, p. 287-304, jul./dez. 2010. 